\section{Modern Explosives}

Number 5 of the Royal Institute of Chemistry "Lectures, Monographs and Reports, 1959" covers the subject of modern explosives (by the late Dr. Wilfrid Taylor. Pp. 63. London: Royal Institute of Chemistry, 1959. 6s. net). It is a well-balanced review of modern chemical explosives, written by one of the most distinguished research workers on the subject who, until his death in 1958, was for many years in the Research Department of the Nobel Division of Imperial Chemical Industries, Ltd. It is an excellent introduction for the chemist, physicist or engineer, to the scientific basis of the development of chemical explosives. Dr. Taylor describes in succession the early history of the development of high explosives, the properties sought from explosives, the chemical composition of the more important individual explosives and of the various commereial mixtures developed from them to suit various requirements. $\mathrm{He}_{\Theta}$ follows with sections on the physical phenomena of detonation (velocity of detonation, temperatures and pressures developed during detonation), and on the precise physical action of explosives in breaking rock and coal. Next is a brief but useful statement of the hydrodynamical theory of detonation, followed by a discussion of modern views of reaction mechanisms in detonation. A special section is devoted to coal-mining explosives, which have to reach the highest possible safety against the danger of ignition of firedamp and coal dust. The whole subject is condensed into sixty very readable pages, with a couple of pages of references carefully selected from among the thousands of original papers on the subject.

\section{A Radiocarbon Dating System using Scintillation Techniques}

A PROCEDURE for radiocarbon dating, based on the use of scintillation techniques, is described by C. F. G. Delaney and I. R. McAulay (Sci. Proc. Roy. Dublin Soc., A, 1, No. 1 ; 1959. 4s.). The method involves the conversion of the sample into methyl alcohol, which is then mixed with a liquid scintillator and its radiocarbon activity measured, in a quartz cell, using an arrangement of two photomultipliers in coincidence. The overall yield in the chemical preparation is about 45 per cent, and the purity of the methyl alcohol is checked by gas-phase chromatography. The background counting-rate is reduced by the use of massive screening combined with the application of the technique of pulse-height selection to the outputs of the photomultipliers. In this way, a background of 13.6 c.p.m. is obtained, and the net counting-rate for contemporary material is $20 \cdot 6$ c.p.m. above this value. Thus, when using a counting period of $17 \mathrm{hr}$, results of significance to 30,000 years are obtainable. The weight of sample required (equivalent to about $15 \mathrm{gm}$. carbon) is rather large compared with the requirements of most of the methods in current use, nearly all of which are based on proportional gas-counting techniques. However, this method, unlike those based in gas counting, has the advantage that it is not dependent on supplies of liquid air (which is not readily available in Dublin). Moreover, the preparative chemistry is relatively simple, and less steel screening is required than is necessary in most arrangements using proportional counters. The initial dating programme was concerned with the dating of vegetational changes detected by pollen analysis in a peat column from
Redbog, Co. Louth, and the results of these measurements are presented.

\section{X-Ray Studies of Some Carbonized Coals}

IN a recent paper, $\mathbf{R}$. Diamond has described a notable advance in the X-ray study of carbonaceous materials (Phil. Trans. Roy. Soc., 252, 193 ; 1959). The paper reviews the author's detailed work with $\mathrm{P}$. B. Hirsch on the X-ray examination of a range of coals carbonized up to $1,000^{\circ} \mathrm{C}$., and brings together the analysis of variations in aromatic layer size distribution, mean $\mathrm{C}-\mathrm{C}$ bond-length and molecular packing in a consistent model of the carbonization process. The approach to the problem of aromatic layer size distribution is particularly interesting not only because it is the first attempt of this kind, but also because of the elegance of the method. The author uses matrix methods in fitting a linear combination of theoretical intensity functions for graphitic layers of various size-groups to the observed X-ray intensities with the minimum total square error. The results are given as histograms showing the percentages by weight of material associated with each size-group. It would seem that this 'resolution' is approaching the limit attainable by $\mathrm{X}$-ray analysis of these complex disordered materials. This is brought out in Diamond's careful discussion of the significance of layer diameter measurements when the structural model is modified to include edge groupings and departures of the aromatic layers from a truly graphitic structure. The structural chemist will want to know more about the nature of the aromatic systems as well as other features which $\mathrm{X}$-ray analysis cannot elucidate, but the facts brought to light in this work should appreciably limit the range for conjecture in a field where it has inevitably been wide.

\section{Culture of Salmon and Trout}

IN many parts of North America, the culture of trout and salmon is carried out on a large scale, and a bulletin recently issued by the Department of Fish and Game for the State of California deals briefly with many aspects of hatchery practice (No. 107: Trout and Salmon Culture--(Hatchery Methods). By Earl Leitritz. Pp. 169. Sacramento : Printing Division, Department of Fish and Game, 1959. 2 dollars). The sections on feeding practices and the treatment of disease serve to illustrate how new methods and techniques have been introduced during the past ten or fifteen years. Comprehensive feeding schedules have been developed from actual production records, and in this way the fish are adequately fed with a minimum of waste and the minimum amount of labour. Various anæsthetics have been employed as an aid in tagging, taking of spawn and the transportation of fish. Until recently, urethane (ethyl carbonate) was perhaps the most common anæsthetic used in fishery work. However, tests with mammals have shown that this substance could be carcinogenic after prolonged and repeated exposures. Because of this risk to fishery workers, urethane is no longer used as a fish anæsthetic in California. As an alternative, MS 222 (tricaine methane sulphonate) is in common use both in the United States and Europe.

This book was prepared at the request of many of the Department's fish hatchery personnel, and naturally it is concerned mainly with the culture of rainbow trout and certain species of Pacific salmon. However, it contains much useful data and practical 